\title{
Trapped bubbles keep pumice afloat and gas diffusion makes pumice sink
}

\author{
Kristen E. Fauria ${ }^{1}$, Michael Manga ${ }^{1}$, and Zihan Wei ${ }^{1,2}$ \\ ${ }^{I}$ Department of Earth and Planetary Science, UC Berkeley, 307 McCone Hall, Berkeley, \\ CA 94720-4767 \\ ${ }^{2}$ Department of Earth and Space Sciences, Peking University, Beijing, China \\ Corresponding author: Kristen E. Fauria, kfauria@berkeley.edu \\ KEYWORDS
}

Buoyancy

Capillary processes

Percolation theory

Submarine volcanism

X-ray microtomography 


\section{ABSTRACT}

24 Pumice can float on water for months to years - long enough for pumice to travel across

25 oceans and facilitate the spread of species. Long-lived pumice floatation is unexpected,

26 however, because pumice pores are highly connected and water wets volcanic glass. As a

27 result, observations of long floating times have not been reconciled with predictions of

28 rapid sinking. We propose a mechanism to resolve this paradox - the trapping of gas

29 bubbles by water within the pumice. Gas trapping refers to the isolation of gas by water

30 within pore throats such that the gas becomes disconnected from the atmosphere and

31 unable to escape. We use X-ray microtomography to image partially saturated pumice

32 and demonstrate that non-condensable gas trapping occurs in both ambient temperature

33 and hot $\left(500^{\circ} \mathrm{C}\right)$ pumice. Furthermore, we show that the size distribution of trapped gas

34 clusters matches predictions of percolation theory. Finally, we propose that diffusion of

35 trapped gas determines pumice floatation time. Experimental measurements of pumice

36 floatation support a diffusion control on pumice buoyancy and we find that floatation

37 time $\tau$ scales as $\tau \propto \frac{L^{2}}{D \theta^{2}}$ where $L$ is the characteristic length of pumice, $D$ is the gas-

38 water diffusion coefficient, and $\theta$ is pumice water saturation. A mechanistic

39 understanding of pumice floatation is a step towards understanding how pumice is

40 partitioned into floating and sinking components and provides an upper bound on the

41 lifetime of pumice rafts in the ocean. 


\section{INTRODUCTION}

Pumice is a highly vesicular volcanic rock with a porosity high enough that it can

48 float. Rafts of volcanic pumice can transit lakes and oceans and circle the globe (e.g.,

49 Richards, 1958; Risso et al., 2002; Bryan et al., 2004; von Lichtan et al., 2016). For

50 example, pumice from the 1952 eruption of Volcán Barcena on Isla San Benedicto, 600

$51 \mathrm{~km}$ west of Mexico, floated for at least 560 days and drifted over $8700 \mathrm{~km}$ (Richards,

52 1958). The 2012 eruption of Havre submarine volcano created a $1.5 \mathrm{~km}^{3}$ pumice raft that

53 spread over 550,000 km² within three months (Carey et al., 2014; Jutzeler et al., 2014).

54 Pumice rafts have been shown to facilitate the dispersal of species such as barnacles,

55 corals, algae, and gastropods (Bryan et al., 2012) because marine organisms grow on, and

56 ocean currents advect, pumice (Richards, 1958; Jokiel, 1984; Bryan et al., 2004). While

57 pumice rafts are relatively common and it is well known that ambient temperature

58 pumice can float for long periods of time, the enduring buoyancy of pumice is surprising

59 because pumice pores are almost entirely connected and water wets pumice (Whitham \&

60 Sparks, 1986; Vella \& Huppert, 2007). Quantitative models for pumice saturation predict

61 that ambient temperature pumice should sink orders of magnitude more rapidly than is

62 observed (Vella \& Huppert, 2007). The floatation time discrepancy between observations

63 and the Vella \& Huppert (2007) model suggests that simple gas displacement by an

64 infiltrating water front is not sufficient to explain why ambient temperature pumice can

65 float for years.

66 By comparison to ambient temperature pumice, hot pumice (e.g., $\left.>300^{\circ} \mathrm{C}\right)$ sinks

67 almost immediately and the tendency for air-filled pumice to sink increases with pumice

68 temperature (Whitham \& Sparks, 1986; Dufek et al., 2007; Allen et al., 2008; Jutzeler et 
69 al., 2016). Rapid water ingestion by hot pumice has been attributed to cooling-induced

70 gas contraction (Whitham \& Sparks, 1986; Cashman \& Fiske, 1991; Allen et al., 2008)

71 and hydrodynamic instabilities due to steam generation (Dufek et al., 2007). Air-filled

72 hot pumice placed in water does not, however, completely saturate even at high $\left(500^{\circ} \mathrm{C}\right)$

73 temperatures (Allen et al., 2008). As a result, we wish to understand how gas remains

74 within initially hot pumice and what differences and similarities exist between saturation

75 of ambient temperature and hot non-condensable gas filled pumice.

76 Pumice, with porosities of 50 to $>90$ percent, is a porous medium. Water

77 saturation of pumice is an example of two-phase flow in porous media and requires the

78 replacement of a defending fluid (air or magmatic gases) with an invading fluid (liquid

79 water). Two-phase flow in porous media has been widely studied in the context of the

80 vadose zone, oil recovery, $\mathrm{CO}_{2}$ sequestration, and gas sparging. In addition, water

81 infiltration of pumice is a manifestation of a particular type of two-phase flow,

82 imbibition, because water is the wetting phase. During imbibition the arrangement of

83 fluid, or wetting pattern, can range from one where nearly all the pores are filled with the

84 invading fluid to one where the defending fluid remains trapped in clusters (e.g.,

85 Lenormand \& Zarcone, 1984). Trapped gas clusters (Figure 1), pockets of non-wetting

86 fluid that are surrounded by the wetting fluid, are not only characteristic of two-phase

87 flow in porous media but are very difficult to mobilize because of surface tension.

88 Indeed, gas trapping is a mechanism employed for long term $\mathrm{CO}_{2}$ sequestration (e.g., Ide

89 et al., 2007; Benson \& Cole, 2008).

90 We hypothesize that pumice floats for long periods of time because of the

91 occurrence of gas trapping (either air or non-condensable magmatic gases) in isolated gas 
92 clusters during water infiltration. We use X-ray microtomography to test the hypotheses

93 that gas trapping occurs in both hot and ambient temperature pumice, that gas trapping

94 can result in a high enough residual gas saturations to keep pumice afloat, and that

95 percolation theory can describe gas trapping in pumice. While trapped gas may buoy

96 pumice, we hypothesize that the outward diffusion of gas trapped in bubbles eventually

97 causes pumice to sink. We test this gas diffusion hypothesis by conducting experiments

98 where we measure the floatation time of dry and ambient temperature pumice on artificial

99 seawater in a controlled laboratory setting. We then compare our results and pumice

100 floatation times from four other studies with a prediction for pumice floatation time based

101 on gas-diffusion out of a porous medium.

\section{1.1 GAS TRAPPING IN POROUS MEDIA}

103 Gas trapping has been observed in experiments, dictates wetting patterns, and

104 controls residual non-wetting saturation of porous media (e.g., Blunt \& Scher, 1995;

105 Iglauer et al., 2013; Geistlinger \& Mohammadian, 2015). A key element that promotes

106 gas trapping is the slow advance of the invading fluid such that capillary forces dominate

107 over viscous forces. In other words, the Capillary number

$108 \mathrm{Ca}=\frac{v \mu}{\gamma}$,

109 where $v$ is the characteristic velocity, $\mu$ is the wetting fluid viscosity, and $\gamma$ is surface

110 tension on the interface between the two fluids, is very small, $\mathrm{Ca}<<1$ (Lenormand \&

111 Zarcone, 1984; Wilkinson, 1984; Blunt \& Scher, 1995).

112 We calculate a Capillary number for water infiltration into dry pumice using $\mu=$

$11310^{-3} \mathrm{~Pa}$ s for the viscosity of water at room temperature, $\gamma=0.072 \mathrm{~N} \mathrm{~m}^{-1}$ for the surface

114 tension at the air-water interface, and by estimating the velocity of water infiltrating 
115 pumice using Darcy's law. For pumice floating on water, the maximum head gradient is

116 set by the hydrostatic pressure at the bottom edge of the pumice and the capillary

117 pressure. By assuming a constant pore radius and a hemispherical gas-water meniscus we

118 can write the liquid velocity as

$119 v=\frac{\kappa}{\mu \phi}\left(\rho g h+\frac{2 \gamma}{R}\right)$

120 where $\kappa$ is permeability, $\phi$ is connected porosity, $\rho$ is water density, $g$ is gravity, $h$ is the

121 height of pumice in water, and $R$ is pore throat radius. Pumice porosities can vary widely,

122 but typical values are 50 to 90 percent (pumice with rock equivalent densities between

1232.4 and $3.0 \mathrm{~g} \mathrm{~cm}^{-3}$ must have porosities of at least 58 to 67 percent, respectively, to

124 initially float). Pumice permeabilities are more difficult to estimate, but measured values

125 range from $10^{-14}-10^{-10} \mathrm{~m}^{2}$ (e.g., Klug \& Cashman, 1996; Tait et al., 1998; Saar \&

126 Manga, 1999; Klug et al., 2002; Rust \& Cashman, 2004, 2011; Muller et al., 2005;

127 Wright et al., 2006, 2009; Degruyter et al., 2010). We note that permeability may also be

128 a function of saturation, i.e., relative permeability is not unity. We consider pumice that is

129 immersed $0.01-1 \mathrm{~m}$ in water and pores that have radii of $0.1-0.001 \mathrm{~mm}$. From these

130 input parameters, $3.8 \times 10^{-11}<\mathrm{Ca}<4.3 \times 10^{-4}$, which shows that capillary forces dominate

131 in pumice.

132 We also use pumice saturation measurements from Whitham \& Sparks (1986) to

133 estimate water infiltration velocities according to,

$134 v=\frac{\Delta V_{w}}{\Delta t S_{a} \phi}$

135 where $V_{w}$ is the volume of absorbed water, $t$ is time, $S_{a}$ is pumice surface area, and $\phi$ is

136 connected porosity. We estimate $S_{a}$ by assuming the pumice clasts are spherical. Fourteen 
137 pumice saturation measurements by Whitham and Sparks (1986) reveal average initial

138 infiltration velocities over the first five minutes of water exposure of $2.74 \pm 0.97 \times 10^{-2} \mathrm{~cm}$

$139 \mathrm{hr}^{-1}$ and Capillary numbers of $7.62 \pm 2.69 \times 10^{-8}$. These Ca estimates indicate that capillary

140 forces dominate. Thus, the saturation of pumice should be considered at the pore scale

141 and may lead to gas trapping. In the next sections we introduce two mechanisms that

142 allow gas trapping to occur, the percolation models that simulate them, and the gas-

143 trapping predictions percolation theory makes.

\section{$144 \quad$ 1.1.1 Bypass trapping}

145 Bypass trapping (Figure 1a) causes trapping through the sequential filling of pore

146 throats such that the defending fluid becomes surrounded by the invading fluid before it

147 can escape (e.g., Chatzis et al., 1983). Invasion percolation models simulate bypass

148 trapping by (1) representing the porous medium as a network of spheres (pores) and

149 cylinders (pore throats); (2) prescribing a capillary entry pressure for each throat and

150 pore; and (3) filling throats and pores from highest to lowest pressure. As a result, a pore

151 or series of pores with low capillary pressures may be completely surrounded before

152 being filled and thus become trapped (but may contract or expand if compressible).

\section{$153 \quad$ 1.1.2 Snap-off trapping}

154 Snap-off trapping occurs because for very low flow rates (or capillary numbers)

155 the wetting fluid can flow along edges of the pore walls due to surface roughness (e.g.,

156 Leonard and Zarcone, 1984). This wall-hugging thin film can swell as the wetting fluid

157 invades. As the film swells in the smallest throats, it completely displaces the non-

158 wetting phase and can disconnect the non-wetting phase from any neighbors (Figure 1b).

159 Snap-off trapping is simulated by Bond percolation. When snap-off and bypass trapping 
160 are both possible, bypass trapping is favored because it occurs for higher capillary

161 pressures.

$162 \quad$ 1.1.3 Percolation model predictions

163 Both invasion and bond percolation theory make predictions about the size

164 distribution of residual trapped gas clusters. Because percolation systems are scale

165 invariant at the critical point (when fully percolated), the number of occurrences, $n(s)$, of

166 trapped gas clusters containing $s$ sites or pores scales according to a power-law,

$167 n(s) \sim s^{-\beta}$,

168 where $\beta=\frac{a+f}{f}$ and $a$ is the spatial dimension and $f$ is the fractal dimension of the

169 cluster. In 3D: $a=3, f=2.52$, and $\beta=2.19$ (Stauffer, 1979; Wilkinson \& Willemsen,

170 1983). The maximum size of the trapped gas cluster is limited by the samples size, $L$,

$171 s_{\max } \sim L^{f}$, (Wilkinson, 1986). Experimental studies of imbibition in porous media have

172 shown that trapped gas size distributions match Equation 4 (e.g., Geistlinger \&

173 Mohammadian, 2015). Examining the size distribution of trapped gas bubbles in a natural

174 system, such as pumice, can therefore help distinguish if percolation theory (either Bond

175 or Invasion) applies.

176 2. X-RAY MICROTOMOGRAPHY

177 X-ray microtomography ( $\mu$ XRT) allows us to see both the internal structure of

178 pumice (e.g., Polacci et al., 2006; Wright et al., 2006; Degruyter et al., 2010; Giachetti et

179 al., 2011; Voltolini et al., 2011; Carey et al., 2013) and, when multiple fluids are present

180 within the pores, the distribution of those fluids (e.g., Wildenschild et al., 2002). We use

$181 \mu \mathrm{XRT}$ to (1) test the hypothesis that gas trapping occurs in pumice; (2) determine if 
182 percolation theory can describe the size distribution of trapped gas; (3) examine the size

183 distribution of trapped gas for insights into the mechanisms (bypass or snap-off trapping)

184 that occur in pumice.

\subsection{Experimental Set-Up}

186 We used $\mu$ XRT to image the internal distribution of liquid and air in six uncut

187 pumice clasts. Before the $\mu$ XRT, we conducted saturation experiments on ambient 188 temperature and hot $\left(500^{\circ} \mathrm{C}\right)$ pumice from Santa Maria, Guatemala and Medicine Lake,

189 California (Table 1). We set ambient temperature pumice on a $13 \mathrm{wt} \%$ solution of

190 potassium iodide (KI) for $\sim 20$ hours such that the pumice could adsorb the liquid. KI, a

191 common chemical dopant, increases contrast of the $\mu$ XRT images (greatly improves the

192 segmentation of air and water in the images), while maintaining a surface tension within

$1931 \%$ of water (Aveyard \& Saleem, 1976; Wildenschild et al., 2002).

194 We heated two of the pumice samples (SM04 and SM05) to $500^{\circ} \mathrm{C}$, quenched

195 these pumice clasts in the KI dopant, and allowed them to stay in the solution for $\sim 10$

196 minutes. All pumice pores were filled with air at the time of KI exposure. To preserve the

197 internal fluid distributions for $\mu$ XRT imaging, we then rapidly removed and encased the 198 pumice in wax.

199 We carried out the $\mu$ XRT imaging at the Lawrence Berkeley National Lab

200 Advanced Light Source on beamline 8.3.2. We conducted the scans using $30 \mathrm{kev}$

201 monochromatic X-Rays and a $5 \mathrm{X}$ lens (resolution of $1.22 \mu \mathrm{m} /$ pixel). We used the

202 TomoPy gridrec algorithm to reconstruct the 3D image stacks (Gürsoy et al., 2014).

203 To minimize ring artifacts, we selected a subvolume from each data set of either

2040.37 or $0.94 \mathrm{~mm}^{3}$ for data processing. We used Fiji's Trainable Weka Segmentation 
205 plugin - which employs multiple machine learning algorithms - to segment air, water, and

206 rock within each image sequence (Hall et al., 2009). To train classifiers for each image

207 sequence, we manually outlined vesicles and trapped air on fifty different images. After

208 checking and retraining the classifiers as necessary, we applied the trained classifiers

209 across the images sequences to segment air and rock (thereby creating two sets of

210 binarized image sequences for each sample).

211 We also made the image sequences binary by applying a greyscale threshold in

212 Fiji, but determined that the machine learning method reduced the effect of annular ring

213 artifacts and better preserved thin glass walls compared to the traditional threshold based

214 binarization method. Despite the advantages of the machine learning method, two image

215 sets (SM02 and SM05) had glass walls that were too thin to resolve and we do not report

216 porosities or vesicle size distributions for these samples.

217 After we segmented each data set, we loaded the binary images into Avizo where

218 we identified and quantified the volume, surface area, and orientation of individual

219 bubbles and vesicles. Here we refer to the pores of the pumice (that can be filled with

220 either gas or liquid) as vesicles and areas where the gas phase is present as bubbles.

221 Because most samples had highly interconnected porosities, we separated connected

222 vesicles using a watershed algorithm before measuring vesicles sizes and orientations

223 (supplementary information). No separation was applied to the gas bubbles. As a result,

224 any observed and reported gas bubbles were truly isolated. We note, however, that some

225 gas bubbles may appear connected (by one or two voxels) when they are not if glass

226 walls are thinner than one pixel. To correct for very thin glass walls we use a 
227 "neighborhood" value of six in the Avizo labeling module such that bubbles must share at

228 least one voxel face to be considered connected.

229 Errors in generating the bubble and vesicle size distributions stem from two main

230 sources: (1) ring artifacts in the original greyscale image and (2) vesicle walls that are

231 thinner than the voxel resolution and that may also lead to overestimates of connected

232 porosity (Figure S1). Through examination of twenty 2D images from each dataset, we

233 estimate that ring artifacts result in the mischaracterization of gas or water in $<1$ volume

234 percent of each pumice. While the machine learning method for image segmentation

235 reduced the effects of ring artifacts compared to threshold based segmentation, it

236 introduced a number of very small (artifact) bubbles and vesicles that do not contribute to

237 the total volume fraction of pores or trapped gas. As a result, we filtered the data to

238 exclude any bubbles or vesicles with less than a 4 pixel radius or smaller than $10^{-6} \mathrm{~mm}^{3}$.

2392.3 X-ray microtomography results

240 We find trapped gas clusters in all pumice we imaged (Figures 2 and 3). Trapped

241 gas cluster size varies and gas clusters fill part of, single, and multiple vesicles (Figures 2

242 and 3). Because connected porosities for most samples are close to or equal to the total

243 porosity, isolated gas pockets are due to trapping by liquid instead of isolation by rock

244 (Table 1). Furthermore, we found that ambient temperature pumice contain larger volume

245 percentages of trapped gas (36 - 50\%) than the hot pumice (13 and 17\%) (Table 1).

246 We use $\mu$ XRT measurements of phase (liquid and water) saturations to estimate

247 pumice buoyancy, assuming glass densities of $2.4 \mathrm{~g} \mathrm{~cm}^{-3}$, and find that the observed

248 trapped gas saturations are high enough to allow pumice to float. These density

249 calculations match our observation that many of the pumice clasts were floating or 
250 neutrally buoyant when we encased them in wax. Our density calculation of ML01,

251 however, does not match our observation that ML01 was not floating (Table 1).

252 Discrepancies between observations and density estimages suggest that gas and liquid

253 saturation within pumice is likely heterogeneous. Indeed, we visually observed areas of

254 more and less gas saturation within $\mu$ XRT images.

255 The size distributions of both trapped gas (black) and segmented pores (grey) are

256 shown in Figure 4. For the majority of samples (ML02, SM01, SM02, and SM05) at least

257 a third of the trapped gas is contained within one large cluster. These clusters, in cases

258 where the vesicle size distributions are known (SM01 and ML02), greatly exceed the

259 maximum vesicle size and Figure 3 shows how these largest trapped bubbles can extend

260 throughout multiple vesicles. The trapped bubble size distributions, however, show that

261 there are multiple modes of trapped bubbles sizes. In sample ML01, the trapped bubble

262 size distribution mirrors the vesicle size distribution.

\subsection{Comparison to Percolation Theories}

264 Here we test the hypothesis that percolation theory can describe gas trapping in

265 pumice by fitting Equation (4) to the observed distribution of trapped gas clusters using

266 the maximum likelihood method (Clauset et al., 2009; Iglauer \& Wülling, 2016). We find

267 that Equation (4) fits the observed distributions well and that fitted power-law

268 coefficients range from $1.51-2.10$, which (other than the coefficient for ML01) are close

269 to the value predicted by percolation theory $(\beta=2.19)$ (Figure 5; Table 1). These power-

270 law fits lend support to a percolation theory treatment of pumice saturation.

$271 \quad$ Percolation theory also predicts:

$272 A \propto V^{p}$, 
273 where $A$ is the surface area of the trapped clusters, and $V$ is the volume of the trapped

274 clusters (Stauffer, 1979). From our data sets, we empirically find $p=0.75-0.83$ and the

$275 \mathrm{R}^{2}$ values for these fits are $0.95-0.99$ (Table 1 and Figure S2). Values of $p$ greater than

$2762 / 3$ demonstrates that the gas bubbles are non-spherical.

\section{3. MECHANISMS THAT CAUSE PUMICE TO SINK}

278 The previous sections demonstrated that gas trapping occurs in pumice, that

279 ambient temperature pumice traps more gas than hot $\left(500^{\circ} \mathrm{C}\right)$ pumice, that gas trapping

280 can lead to high enough residual gas saturations to allow pumice to float, and that

281 percolation theory can describe the distribution of trapped gas clusters. The occurrence of

282 gas trapping does not, however, explain why pumice, after floating for days or months,

283 eventually sinks.

\section{$284 \quad 3.1$ Pumice floatation experiments}

285 To examine why pumice sinks, we conducted pumice floatation experiments 286 using pumice from the 1902 plinian eruption of Santa Maria Volcano, Guatemala. We

287 placed the pumice in artificial seawater and measured the time it took for the pumice to 288 sink. Before the experiments, we cleaned the pumice in an ultrasonicator for four hours

289 and dried the pumice in an oven at $65^{\circ} \mathrm{C}$ for 12 hours. We specifically chose a

290 temperature lower than $100^{\circ} \mathrm{C}$ to ensure that we did not break pumice walls during the

291 drying process and used $\mu$ XRT to confirm that the pumice was dry prior to experiments.

292 Table 2 shows the pumice weights, sizes, and characteristics. While we did not measure

293 the volume of each pumice clast, we estimated volume by assuming porosities of $80 \%$

294 and glass densities of $2.4 \mathrm{~g} \mathrm{~cm}^{-3}$. 
To initiate the floatation experiments, we dropped the pumice from a height of 4

$296 \mathrm{~cm}$ into individual containers of artificial seawater. These containers were covered to

297 prevent evaporation and contamination. We monitored the pumice with a time lapse

298 camera that could determine when each clast sank to the nearest minute.

\section{$299 \quad 3.2$ Pumice floatation timescale}

$300 \quad$ Here we propose that the diffusion of trapped gas bubbles out of the pumice (and

301 eventually to the atmosphere) causes pumice containing trapped gas clusters to sink. We

302 envisage that the diffusion process is analogous to Ostwald ripening where small (and

303 thus higher pressure) trapped gas clusters diffuse into larger clusters and eventually to the

304 atmosphere. If gas diffusion does control pumice buoyancy through time, then pumice

305 floatation time should scale like a diffusive process where

$306 \tau \sim \frac{L^{2}}{D_{e f f}}$,

307 and where $L$ is the mean diameter of the pumice, and $D_{\text {eff }}$ is the effective diffusion

308 coefficient. The effective diffusion coefficient for trapped gas in pumice, as in other

309 porous media, is not just the gas-liquid diffusion coefficient, but should be weighted by

310 the connectivity of the porous media (i.e., porosity and partial saturation). From Hunt et

311 al. (2014) we write effective diffusivity as $D_{\text {eff }}=D \theta^{2}$, where $\theta$ is water saturation

312 (fraction of pore space filled by water) and $D$ is the liquid-gas diffusion coefficient, such

313 that

$314 \tau \propto \frac{L^{2}}{D \theta^{2}}$.

315 We test the hypothesis that diffusion of trapped gas out of pumice allows pumice

316 to sink by comparing experimental measurements of pumice floatation time and volume 
317 (Whitham and Sparks, 1986; Manville et al., 1998; Risso et al., 2002; White et al., 2001)

318 with Equation (6) and where $L \sim V^{2 / 3}$ (Figure 6). Because we do not know $\theta$ for any

319 individual pumice, and because, if our hypothesis is correct, $\theta$ changes through time, we

320 consider Equation (6) with a range of saturation values (8 - 80\%).

\section{$321 \quad 3.3$ Pumice floatation results and model comparison}

322 Figure 6 shows measurements of floatation time and volume (this study and four others)

323 against predictions from Equation (6) and where $D=1.9 \times 10^{-5} \mathrm{~cm}^{2} \mathrm{~s}^{-1}$ is the air-water

324 diffusion coefficient at room temperature. Experimental measurements of pumice

325 floatation times generally match predictions from Equation (6) (Figure 6). We also list

326 pumice floatation times from our experiments in Table 2.

327 It is worth noting, however, that if pumice are highly non-spherical, then we

328 overestimate the effective length scale (shortest pumice axis). Furthermore, the timescale

329 for pumice floatation may depend strongly on $\theta$, not only because $\theta$ affects the

330 diffusivity, but also because more diffusion must occur to sink a pumice with an initially

331 high trapped gas content.

332 While we are not the first to recognize that pumice floatation time scales like a

333 diffusive process (Manville et al., 1998), diffusion of trapped gas out of the pumice has

334 not previously been identified to be the controlling process. Figure 6, in combination with

335 observations of gas trapping, suggests that it is the diffusion of trapped gas out of pumice

336 that causes raft and other floating pumice to eventually sink.

337 4. DISCUSSION

$338 \quad 4.1$ Gas trapping timescale 
339 We find that water saturation of pumice is a two-step process. First, capillary and

340 hydrostatic pressures drive water into pores. Water invasion often leads to gas trapping

341 (e.g. section 1.1) and ends when there are no longer pores to invade. Second, gas slowly

342 diffuses out of trapped gas pockets thereby creating more space for the liquid (section 3).

343 Here we estimate the timescale for the first of these processes - the time for pumice to

344 reach its residual saturation state.

345 If pumice can be modeled as a bundle of horizontal parallel cylindrical tubes and

346 capillary pressures drive fluid into the tubes, then the Washburn equation can describe the

347 timescale for water saturation over horizontal distance $L$,

$348 \quad t=\frac{4 L^{2} \mu}{\gamma d}$,

349 where $d$ is mean pore throat diameter. Equation (7) suggests that pumice with $0.05 \mathrm{~mm}$

350 diameter pores should reach its residual saturation state very rapidly: 2.7 seconds for 5

$351 \mathrm{~cm}$ pumice and 18 minutes for $1 \mathrm{~m}$ pumice. In other words, if a dry pumice is set on

352 water, then capillary forces draw in liquid quickly and set the wetting pattern and trapped

353 gas geometry in timescale, $t$. We emphasize that pumice can remain buoyant following

354 water invasion due to gas trapping.

$355 \quad 4.2$ Water saturation of hot versus cold pumice

356 We find that residual gas saturation is lower for hot pumice $\left(500^{\circ} \mathrm{C}\right)$ compared to

357 ambient temperature pumice, and that these lower gas saturations can account for the

358 buoyancy differences of hot versus cold pumice (Table 1). Because hot pumice may

359 rapidly saturate due to non-condensable gas contraction (Whitham \& Sparks, 1986;

360 Cashman \&Fiske, 1991; Allen et al., 2008), we compare the pressure differences 
361 generated by three processes that can drive fluid into pumice: water column weight,

362 capillary action, and gas cooling and contraction.

363 Gravity induces a pressure difference when pumice is submerged in water

364 proportional to,

$365 \Delta P=\left(\rho_{l}-\rho_{g}\right) g L \sim 10^{3} \mathrm{~Pa}$,

366 choosing $L=10 \mathrm{~cm}$. The pressure difference induced by capillary forces is,

$367 \Delta P=\frac{2 \gamma}{R} \sim 1.5 \times 10^{4} \mathrm{~Pa}$,

368 where $R=10 \mu \mathrm{m}$ is pore throat radius. Lastly, the pressure difference created by gas

369 contraction is proportional to the change in temperature of the gas by the ideal gas law

370 such that

371

$$
\Delta P=P_{i} \frac{\Delta T}{T_{i}} .
$$

372 Assuming that the initial pressure, $P_{i}$, of the gas is atmospheric $\left(\sim 10^{5} \mathrm{~Pa}\right)$, the initial

373 temperature of the gas, $T_{i}$, is $800 \mathrm{~K}$, and the change in gas temperature, $\Delta T$, is $500 \mathrm{~K}$,

374 then $\Delta P \sim 3.7 \times 10^{4} \mathrm{~Pa}$.

375 Gas contraction can thereby produce pressure differences as large as those

376 produced by capillary forces which suggests that, because pressure gradients drive fluid

377 flow, gas contraction can be a relevant process for liquid ingestion. Furthermore, we

378 expect that heat transfer from pumice to liquid is rapid $(<1 \mathrm{~s})$ because pumice walls are

379 very thin,

$380 t \sim L_{w}{ }^{2} / D_{w}$, 
381 where $L_{w} \sim 10^{-5}-10^{-6} \mathrm{~m}$ is the glass wall thickness (Figure 2) and $D_{w} \sim 10^{-7} \mathrm{~m}^{2} \mathrm{~s}^{-1}$ is

382 water thermal diffusivity. Rapid heat transfer suggests that gas contraction occurs

383 simultaneously with capillary induced pore filling. We note, however, that gas

384 contraction may not proceed prior to pore filling because hot gas must contact cool liquid

385 for heat transfer (e.g., Stroberg et al., 2010).

386 Following the derivation of the Washburn equation (Equation 7), we derive a new

387 timescale for the initial stage of water ingestion into pumice when both gas contraction

388 and capillary forces drive fluid flow:

389

$$
t=\frac{4 \mu L^{2}}{R^{2}\left(\frac{2 \gamma}{R}+\frac{P_{i} \Delta T}{T_{i}}\right)}
$$

390 Gas contraction in hot pumice may help to explain the differences in residual gas

391 saturation of hot and cold pumice. When pressure doesn't change, according to the ideal

392 gas law

$$
\frac{V_{i}}{V_{f}}=\frac{T_{i}}{T_{f}}
$$

394 where $V_{i}$ and $T_{i}$ are initial volume and temperature of gas within a pumice and $V_{f}$ and $T_{f}$

395 are final volume and temperature, respectively. We therefore expect that when air is

396 cooled from 800 to $300 \mathrm{~K}, V_{f}=0.37 V_{i}$. Our experiments showed that hot pumice

397 contained gas in $\sim 23 \%$ of pore space while ambient temperature pumice retained gas in

$39854-79 \%$ of its pore space. This reduction in trapped gas volume is $\sim 0.23 / 0.7=0.32$ and

399 is approximately the value $(0.37)$ predicted by gas contraction alone.

$400 \quad$ Trapped bubble size distributions matched percolation theory for both hot and 401 ambient temperature pumice (Figure 5). Invasion percolation theory works by prescribing 
402 a capillary entry pressure for each pore and filling pores from highest to lowest entry

403 pressure. Percolation theory may apply to hot and non-condensable gas-filled pumice

404 because gas contraction introduces a new, yet additive, pressure difference across each

405 pore and thus does not fundamentally change the mechanism for pore filling.

$406 \quad 4.3$ Bypass versus snap-off trapping

407 While the fit of Equation (4) to the measured trapped gas bubble size distributions

408 supports a percolation theory control on pumice saturation, we have yet to determine if

409 gas is trapped by bypass or snap-off mechanisms. The trapped bubble area-to-volume

410 ratios show that the trapped bubbles are non-spherical (Table 1). Furthermore, we

411 observe trapped gas within many interconnected pores (Figure 3). Because snap-off

412 trapping leads to gas bubbles trapped in single pores (e.g., Figure 1), these observations

413 support a bypass trapping mechanism. Furthermore, bypass trapping is topologically

414 favored over snap-off trapping when both are possible.

\section{$415 \quad$ 4.4 Gas diffusion model}

416 In section 3 we demonstrated that the slow diffusion of trapped gas bubbles

417 causes pumice to eventually sink. Here we plot solutions to the diffusion equation to

418 examine how pumice floatation time varies as a function of pumice size, porosity, and

419 initial trapped gas saturation. To write a solution to the diffusion equation we make

420 several assumptions: (1) pumice is spherical; (2) the binary water+gas mixture in pumice

421 can be described as a continuum, (3) initial trapped gas saturation is uniform within the

422 pumice, (4) the diffusion coefficient is constant, (5) pumice pores are entirely connected,

423 and (6) the pumice is entirely submersed in water. With these assumptions in place, the

424 average saturation $\xi$ (gas volume/pore volume) in a spherical pumice of diameter $L$, with 
425 initial interior gas saturation $\xi_{i}$, and with gas saturation equal to zero at the boundaries \pm $426 \mathrm{~L} / 2$ is

428 (Carslaw and Jaeger, 1959; Maneville et al., 1998). Here we let $D_{\text {eff }}=D \theta_{i}^{2}=D\left(1-\xi_{i}\right)^{2}$ (e.g.,

429 Equation 6). Pumice sinks when its average density is equal to the density of the

430 surrounding liquid such that

$431 \quad(1-\phi) \rho_{r}+\phi\left(1-\xi^{*}\right) \rho_{l}=\rho_{l}$,

432 where $\rho_{r}$ is the density of the solid phase, $\xi^{*}$ is the gas saturation when a pumice is

433 neutrally buoyant and $\rho_{l}$ is the liquid density.

434 By combining Equations (14) and (15) we can calculate pumice floatation time,

435 the time it takes a pumice to reach gas saturation $\xi^{*}$, as a function of pumice size $L$,

436 porosity $\phi$, and initial gas saturation $\xi_{i}$. Figure 7 shows solutions to Equations (14) and

437 (15) using contours of constant floatation time. Figure 7 explores how pumice size,

438 porosity, and initial gas saturation affect pumice floatation. We find that high porosity

439 pumice need higher initial gas saturations to float for the same period of time as lower

440 porosity pumice. Pumice size and porosity vary inversely along contours of constant

441 floatation time and, for constant $\phi$ and $\xi_{i}$, larger pumice float longer.

\section{5. CONCLUSIONS}

443 In this paper, we explore the processes that allow pumice to float and sink. To do

444 this, we studied pumice saturation at the scale of pore level processes where capillary

445 forces may be relevant. From estimates of the capillary number - which indicate that

446 surface tension dominates over viscous forces in pumice - we hypothesized that pumice 
447 can trap isolated gas bubbles as water infiltrates its pores. We used X-ray

448 microtomography to determine if gas trapping occurs in pumice and found that both

449 ambient temperature and hot $\left(500^{\circ} \mathrm{C}\right)$ pumice trap gas. We observed, however, that hot

450 pumice traps far less gas than ambient temperature pumice, consistent with the

451 observation that hot pumice $\left(>300^{\circ} \mathrm{C}\right)$ often sinks after contact with water (Whitham \&

452 Sparks, 1986; Allen et al., 2008; Jutzeler et al., 2016). That is, cold pumice can trap

453 enough gas to keep the pumice afloat while gas contraction in hot pumice leads to lower

454 residual gas saturations.

455 We examined the size distributions of trapped gas in both hot and ambient

456 temperature pumice and found that the distributions fit a power-law prediction from

457 percolation theory. The power-law fits support a percolation theory treatment of water

458 infiltration into pumice.

459 While trapped gas can buoy pumice, we hypothesized that outward diffusion of

460 the trapped gas clusters causes pumice to eventually sink. We quantified this hypothesis

461 with a model for pumice floatation time in terms of trapped gas diffusion (Equation 6).

462 To test the gas diffusion hypothesis, we conducted pumice floatation experiments and

463 compared Equation (6) to our results as well as data from four other studies. We found

464 that the observed pumice floatation times match a trapped gas diffusion prediction

465 (Figure 6). Furthermore, we plot solutions to the diffusion equation on a sphere to explore

466 pumice porosity, size, and initial gas saturation affect floatation time (Figure 7).

467 A mechanistic explanation for pumice floatation is an important step towards

468 understanding when and how pumice is partitioned into rafts versus submarine deposits

469 (e.g., Cashman \& Fiske, 1991; Allen \& McPhie, 2009; Rotella et al., 2013; Cas and 
470 Giordano, 2014). Indeed, submarine volcanic deposits may not record eruption dynamics

471 because non-condensable (i.e., $\mathrm{CO}_{2}$ or air) gas trapping can make pumice buoyant.

472 Furthermore, our results suggest that the lifetime of buoyant pumice rafts is not just

473 limited by pumice abrasion (e.g., Carey et al., 2001; White et al., 2001), but also by gas

474 diffusion. Non-condensable gas trapping and diffusion, by controlling pumice buoyancy,

475 are therefore important controls on the transport and fate of pumice in the marine

476 environment and location in the rock record.

\section{ACKNOWLEDGMENTS}

478 X-ray microtomography was enabled by access to the Lawrence Berkeley National Lab

479 Advanced light source on beamline 8.3.2. We thank Dula Parkinson for guidance with

$480 \mu$ XRT imaging and image processing. A stimulating conversation with Alan Rempel

481 helped to develop the initial gas trapping hypothesis. We thank Tushar Mittal for

482 suggesting the machine learning segmentation algorithm and Steve Breen for informative

483 discussions on percolation theory and for reviewing an earlier version of this manuscript.

484 We thank Ray Cas, Thomas Giachetti, and EPSL editor Tamsin Mather for thoughtful

485 reviews that contributed to this manuscript. Finally, we are grateful for support from Judy

486 Webb and the US National Science Foundation. Data and code used in this study are

487 available on VHub at https://vhub.org/resources/4117.

\section{REFERENCES}

489 Allen, S. R., Fiske, R. S., \& Cashman, K. V. (2008). Quenching of steam-charged

490 pumice: Implications for submarine pyroclastic volcanism. Earth and Planetary

491 Science Letters, 274(1-2), 40-49. http://doi.org/10.1016/j.epsl.2008.06.050 
492

493

494

495

496

497

498

499

500

501

502

503

504

505

506

507

508

509

510

511

512

513

Allen, S. R., \& McPhie, J. (2009). Products of neptunian eruptions. Geology, 37(7), 639642.

Aveyard, R. \& Saleem, S.M. (1975). Interfacial Tensions at Alkane-Aqueous Electrolyte Interfaces, Journal of the Chemical Society, Faraday Transactions 1: Physical Chemistry in Condensed Phases, 72, 1609-1617..

Benson, S. M., \& Cole, D. R. (2008). CO2 sequestration in deep sedimentary formations. Elements, 4(5), 325-331. http://doi.org/10.2113/gselements.4.5.325

Blunt, M. J., \& Scher, H. (1995). Pore-level modeling of wetting. Physical Review E, 52(6), 6387-6403. http://doi.org/10.1103/PhysRevE.52.6387

Bryan, S. E., Cook, a., Evans, J. P., Colls, P. W., Wells, M. G., Lawrence, M. G., ... Leslie, R. (2004). Pumice rafting and faunal dispersion during 2001-2002 in the Southwest Pacific: Record of a dacitic submarine explosive eruption from Tonga. Earth and Planetary Science Letters, 227(1-2), 135-154. http://doi.org/10.1016/j.epsl.2004.08.009

Bryan, S. E., Cook, A. G., Evans, J. P., Hebden, K., Hurrey, L., Colls, P., ... Firn, J. (2012). Rapid, long-distance dispersal by pumice rafting. PLOS ONE, 7(7). http://doi.org/10.1371/journal.pone.0040583

Carey, S., Morelli, D., Sigurdsson, H., \& Bronto, S. (2001). Tsunami deposits from major explosive eruptions: an example from the 1883 eruption of Krakatau. Geology, 29(4), 347-350. doi: 10.1130/0091-7613(2001) 
514 Carey, R. J., Manga, M., Degruyter, W., Gonnermann, H., Swanson, D., Houghton, B., ...

515 \& Patrick, M. (2013). Convection in a volcanic conduit recorded by bubbles.

$516 \quad$ Geology, 41(4), 395-398.

517 Carey, R. ., Wysoczanski, R., Wunderman, R., \& Jutzeler, M. (2014). Discovery of the

518 Largest Historic Silicic Submarine Eruption. Eos, Transactions American

519 Geophysical Union, 95(19), 2012-2014.

520 Cas, R. A., \& Giordano, G. (2014). Submarine volcanism: a review of the constraints,

521 processes and products, and relevance to the Cabo de Gata volcanic succession.

$522 \quad$ Italian Journal of Geosciences, 133(3), 362-377.

523 Cashman, K. V., \& Fiske, R. S. (1991). Fallout of pyroclastic debris from submarine

$524 \quad$ volcanic eruptions. Science(Washington), 253(5017), 275-280.

525 Chatzis, I., Morrow, N., \& Lim, H. (1983). Magnitude and detailed structure of

526 residual oil saturation. Old SPE Journal, 23(2), 311-326. http://doi.org/10.2118/10681-PA

528 Carslaw, H. S., \& Jaeger, J. C. (1959). Conduction of heat in solids. Oxford: Clarendon $529 \quad$ Press, 1959, 2nd ed.

530 Clauset, A., Shalizi, C. R., \& Newman, M. E. (2009). Power-law distributions in 531 empirical data. SIAM review, 51(4), 661-703.

532 http://dx.doi.org/10.1137/070710111

533 Degruyter, W., Bachmann, O., \& Burgisser, A. (2010). Controls on magma

534 permeability in the volcanic conduit during the climactic phase of the Kos

535 Plateau Tuff eruption (Aegean Arc). Bulletin of Volcanology, 72(1), 63-74.

536 http://doi.org/10.1007/s00445-009-0302-x 
537 Dufek, J., Manga, M., \& Staedter, M. (2007). Littoral blasts: Pumice-water heat transfer 538 and the conditions for steam explosions when pyroclastic flows enter the ocean.

539 Journal of Geophysical Research: Solid Earth, 112(B11).

540 Geistlinger, H., \& Mohammadian, S. (2015). Capillary trapping mechanism in

541 strongly water wet systems: Comparison between experiment and percolation

542 theory. Advances in Water Resources, 79, 35-50.

$543 \quad$ http://doi.org/10.1016/j.advwatres.2015.02.010

544 Giachetti, T., Burgisser, A., Arbaret, L., Druitt, T. H., \& Kelfoun, K. (2011). Quantitative

545 textural analysis of Vulcanian pyroclasts (Montserrat) using multi-scale X-ray

546 computed microtomography: comparison with results from 2D image analysis.

547 Bulletin of volcanology, 73(9), 1295-1309.

548 Gürsoy, D., De Carlo, F., Xiao, X., \& Jacobsen, C. (2014). TomoPy: a framework for the 549 analysis of synchrotron tomographic data. Journal of synchrotron radiation, 21(5), $550 \quad 1188-1193$.

$551 \quad$ http://doi.org/10.1107/S1600577514013939

552 Hall, M., Frank, E., Holmes, G., Pfahringer, B., Reutemann, P., \& Witten, I. H. (2009).

553 The WEKA data mining software: an update. $A C M$ SIGKDD explorations

$554 \quad$ newsletter, 11(1), 10-18.

$555 \quad$ http://doi.org/10.1145/1656274.1656278

556 Hunt, A., Ewing, R., \& Ghanbarian, B. (2014). Percolation theory for flow in porous $557 \quad$ media (Vol. 880). Springer.

558 Ide T., S., Jessen, K., \& Orr, F. M. (2007). Storage of CO2 in saline aquifers: Effects of 559 gravity, viscous, and capillary forces on amount and timing of trapping. 
International Journal of Greenhouse Gas Control, 1(4), 481-491. http://doi.org/10.1016/S1750-5836(07)00091-6

562 Iglauer, S., Paluszny, A., \& Blunt, M. J. (2013). Simultaneous oil recovery and residual 563 gas storage: A pore-level analysis using in situ X-ray micro-tomography. Fuel, 103, 905-914. http://doi.org/10.1016/j.fuel.2012.06.094

565 Iglauer, S., \& Wülling, W. (2016). The scaling exponent of residual non-wetting phase

566 cluster size distributions in porous media. Geophysical Research Letters. http://doi.org/ 10.1002/2016GL071298

568 Jokiel, P. L. (1984). Long distance dispersal of reef corals by rafting. Coral Reefs, 3(2), 113-116. http://doi.org/10.1007/BF00263761

570 Jutzeler, M., Marsh, R., Carey, R. J., White, J. D. L., Talling, P. J., \& Karlstrom, L. (2014).

571 On the fate of pumice rafts formed during the 2012 Havre submarine eruption.

$572 \quad$ Nature Communications, 5, 3660. http://doi.org/10.1038/ncomms4660.

573 Jutzeler, M., M. Manga, J.D.L. White, P.J. Talling, A.A. Proussevitch, S.F.L. Watt, M.

574 Cassidy, R.N. Taylor, A. Le Friant, and O. Ishizuka, Submarine deposits from pumice-rich pyroclastic density currents dispersing over water: an

578 Klug, C., \& Cashman, K. V. (1996). Permeability development in vesiculating outstanding example from offshore Montserrat (IODP 340), Bulletin of the Geological Society of America, in press.

581 Klug, C., Cashman, K., \& Bacon, C. (2002). Structure and physical characteristics of 582 pumice from the climactic eruption of Mount Mazama (Crater Lake), Oregon. 583 Bulletin of Volcanology, 64(7), 486-501. http://doi.org/10.1007/s00445-002- 
585 Lenormand, R., \& Zarcone, C. (1984). Role of roughness and edges during imbibition in 586 square capillaries. In SPE annual technical conference and exhibition. Society of $587 \quad$ Petroleum Engineers.

588 Manville, V., White, J. D. L., Houghton, B. F., \& Wilson, C. J. N. (1998). The saturation 589 behaviour of pumice and some sedimentological implications. Sedimentary Geology, 119(1-2), 5-16. http://doi.org/10.1016/S0037-0738(98)00057-8

591 Polacci, M., Baker, D. R., Mancini, L., Tromba, G., \& Zanini, F. (2006). Three592 dimensional investigation of volcanic textures by X-ray microtomography and 593 implications for conduit processes. Geophysical Research Letters, 33(13).

594 Richards, A. F. (1958). Transpacific distribution of floating pumice from Isla San 595 Benedicto, Mexico. Deep Sea Research (1953), 5(1), 29-35. http://doi.org/http://dx.doi.org/10.1016/S0146-6291(58)80005-3

597 Risso, C., Scasso, R. A., \& Aparicio, A. (2002). Presence of large pumice blocks on 598 Tierra del Fuego and South Shetland islands shorelines, from 1962 South 599 Sandwich Islands eruption. Marine Geology, 186(3-4), 413-422.

$600 \quad$ http://doi.org/10.1016/S0025-3227(02)00190-1

601 Rust, A. C., \& Cashman, K. V. (2004). Permeability of vesicular silicic magma: Inertial 602 and hysteresis effects. Earth and Planetary Science Letters, 228(1-2), 93-107. 603 http://doi.org/10.1016/j.epsl.2004.09.025

604 Rust, A. C., \& Cashman, K. V. (2011). Permeability controls on expansion and size 605 distributions of pyroclasts. Journal of Geophysical Research: Solid Earth, 606 116(11), 1-17. http://doi.org/10.1029/2011JB008494 
607 Saar, M. O., \& Manga, M. (1999). Permeability-porosity relationships in vesicular

608 basalts. Geophysical Research Letters, 26(1), 111-114.

609 Stauffer, D. (1979). Scaling Theory of Percolation Clustgers. Physics Reports-Review

$610 \quad$ Section of Physics Letters, 54(1), 1-74.

611 Stroberg, T. W., Manga, M., \& Dufek, J. (2010). Heat transfer coefficients of natural

612 volcanic clasts. Journal of Volcanology and Geothermal Research, 194(4), 214-219.

613 Tait, S., Thomas, R., Gardner, J., \& Jaupart, C. (1998). Constraints on cooling rates and

614 permeabilities of pumice in an explosive eruption jet from colour and magnetic

615 mineralogy. Journal of Volcanology and Geothermal Research, 86(1-4), 79-91.

616 http://doi.org/10.1016/S0377-0273(98)00075-4

617 Vella, D., \& Huppert, H. E. (2007). The waterlogging of floating objects. Journal of

$618 \quad$ Fluid Mechanics, 585, 245. http://doi.org/10.1017/S002211200700715X

619 Voltolini, M., Zandomeneghi, D., Mancini, L., \& Polacci, M. (2011). Texture analysis of

620 volcanic rock samples: quantitative study of crystals and vesicles shape preferred

621 orientation from X-ray microtomography data. Journal of Volcanology and

622 Geothermal Research, 202(1), 83-95.

623 von Lichtan, I. J., White, J. D. L., Manville, V., \& Ohneiser, C. (2016). Giant rafted

624 pumice blocks from the most recent eruption of Taupo volcano, New Zealand:

625 Insights from palaeomagnetic and textural data. Journal of Volcanology and

$626 \quad$ Geothermal Research, 318, 73-88.

627 White, J. D. L., Manville, V., Wilson, C. J. N., Houghton, B. F., Riggs, N. R., \& Ort, M.

628 (2001). Settling and deposition of AD 181 Taupo pumice in lacustrine and

629 associated environments, in White, J.D.L, and Riggs, N.R., eds., Volcaniclastic 

doi:10.1002/9781444304251.ch7

632 Whitham, A.G., \& Sparks, R. S. J. (1986). Pumice, Bulletin of Volcanology, 48(4), 209633223.

634 Wildenschild, D., Vaz, C. M. P., Rivers, M. L., Rikard, D., \& Christensen, B. S. B. (2002).

635 Using X-ray computed tomography in hydrology: Systems, resolutions, and 636 limitations. Journal of Hydrology, 267(3-4), 285-297.

637 http://doi.org/10.1016/S0022-1694(02)00157-9

638 Wilkinson, D., \& Willemsen, J. F. (1983). Invasion percolation: a new form of 639 percolation theory. Journal of Physics A: Mathematical and General, 16(14), $640 \quad 3365-3376$. http://doi.org/10.1088/0305-4470/16/14/028

641 Wilkinson, D. (1984). Percolation model of immiscible displacement in the presence of $642 \quad$ buoyancy forces. Physical Review A, 30(1), 520.

643 Wilkinson, D. (1986). Percolation effects in immiscible displacement. Physical Review A, $644 \quad 34(2), 1380$.

645 Wright, H. M. N., Roberts, J. J., \& Cashman, K. V. (2006). Permeability of anisotropic 646 tube pumice: Model calculations and measurements. Geophysical Research 647 Letters, 33(17), 2-7. http://doi.org/10.1029/2006GL027224

648 Wright, H. M. N., Cashman, K. V., Gottesfeld, E. H., \& Roberts, J. J. (2009). Pore 649 structure of volcanic clasts: Measurements of permeability and electrical 650 conductivity. Earth and Planetary Science Letters, 280(1-4), 93-104. 651 http://doi.org/10.1016/j.epsl.2009.01.023

\section{FIGURES}



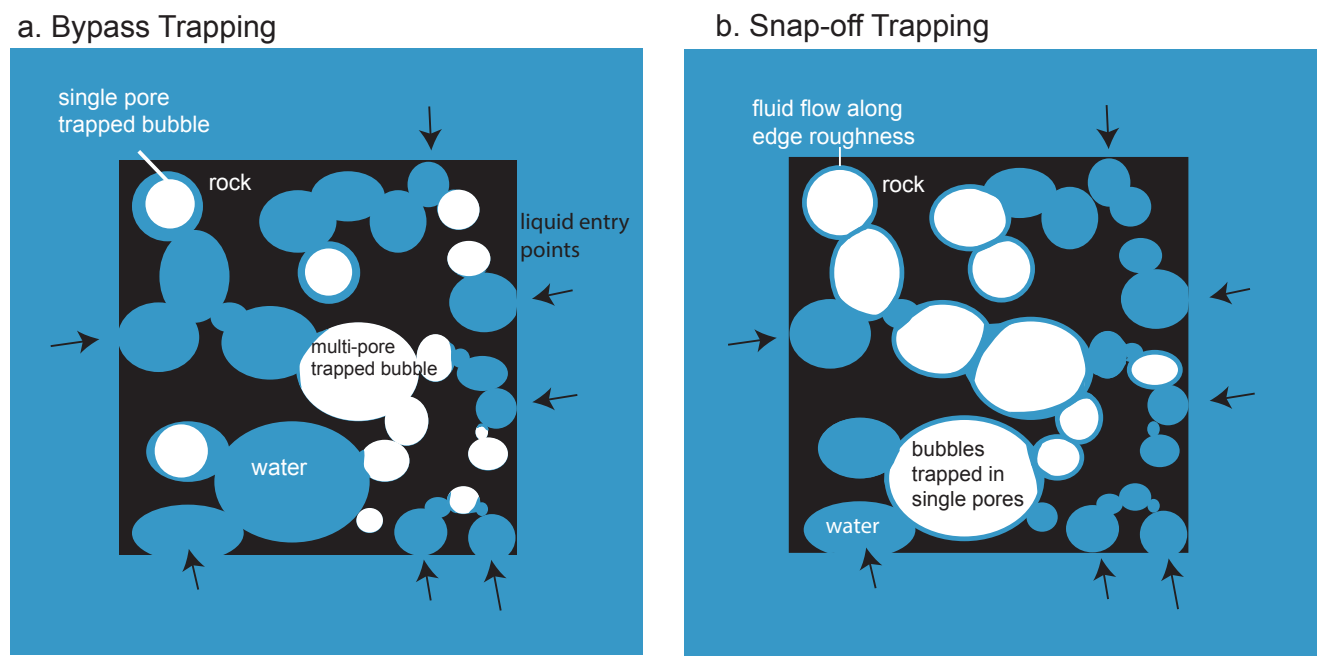

653

654 Figure 1: Mechanisms of gas trapping. Illustrations of gas trapping by (a) bypass and (b)

655 snap-off trapping in pumice with connected pores. In both cases capillary forces draw

656 water into pores such that water completely surrounds the gas phase and the gas is unable 657 to escape.

658 

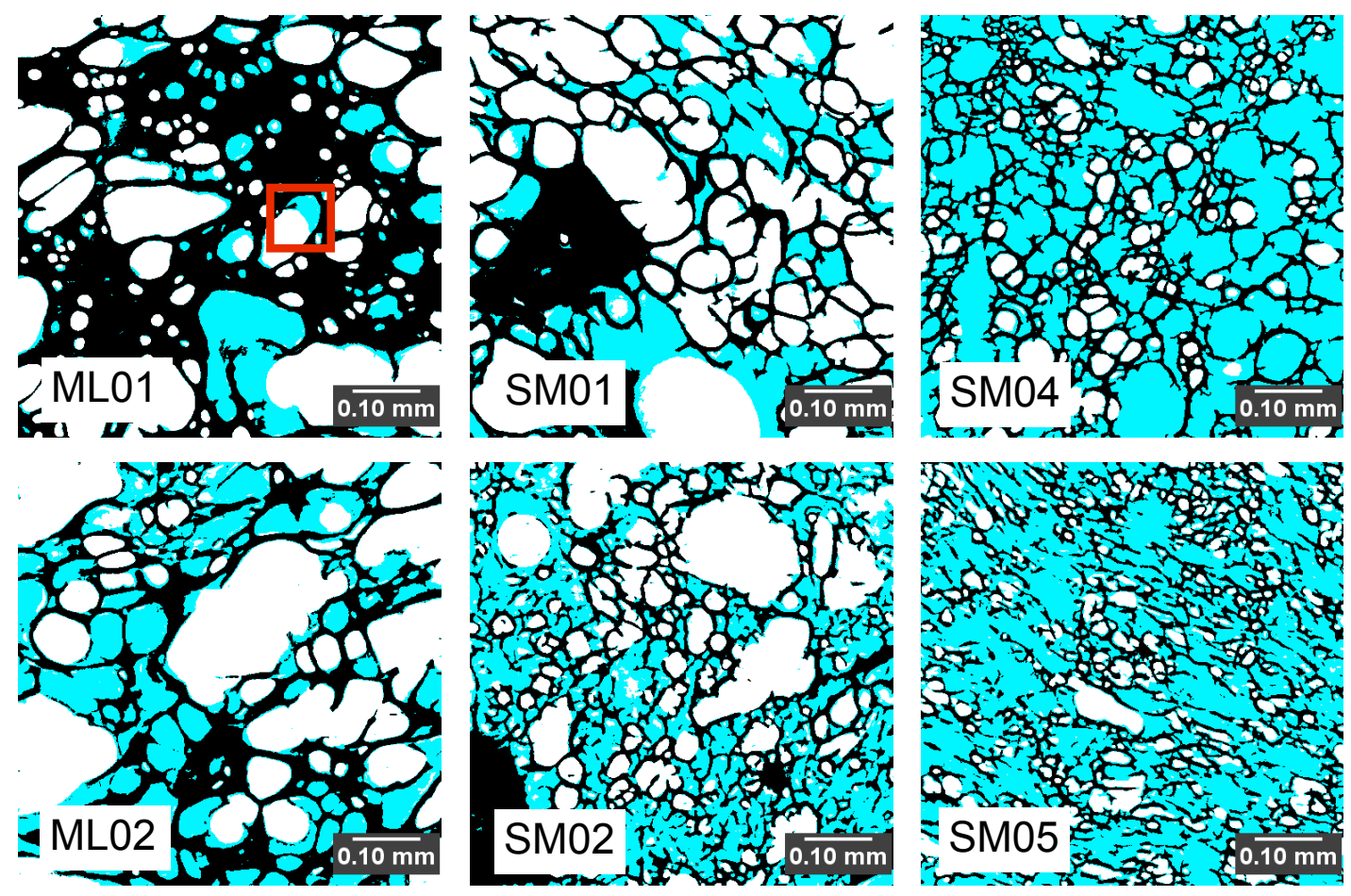

660 Figure 2: X-ray microtomography images. 2D $\mu$ XRT images of pumice containing water

661 and trapped gas. While hot pumice (SM04 and SM05) contain trapped gas, they hold

662 smaller volume percentages compared to ambient temperature pumice. Contacts between

663 rock, liquid, and gas demonstrate that the liquid is the wetting fluid (see red box). While

664 glass walls are too thin to resolve in places (particularly in SM02 and SM05), we do not

665 see any evidence in the $\mu$ XRT that the thin glass walls in pumice are broken or damaged

666 due to cleaning in an ultrasonic bath. 

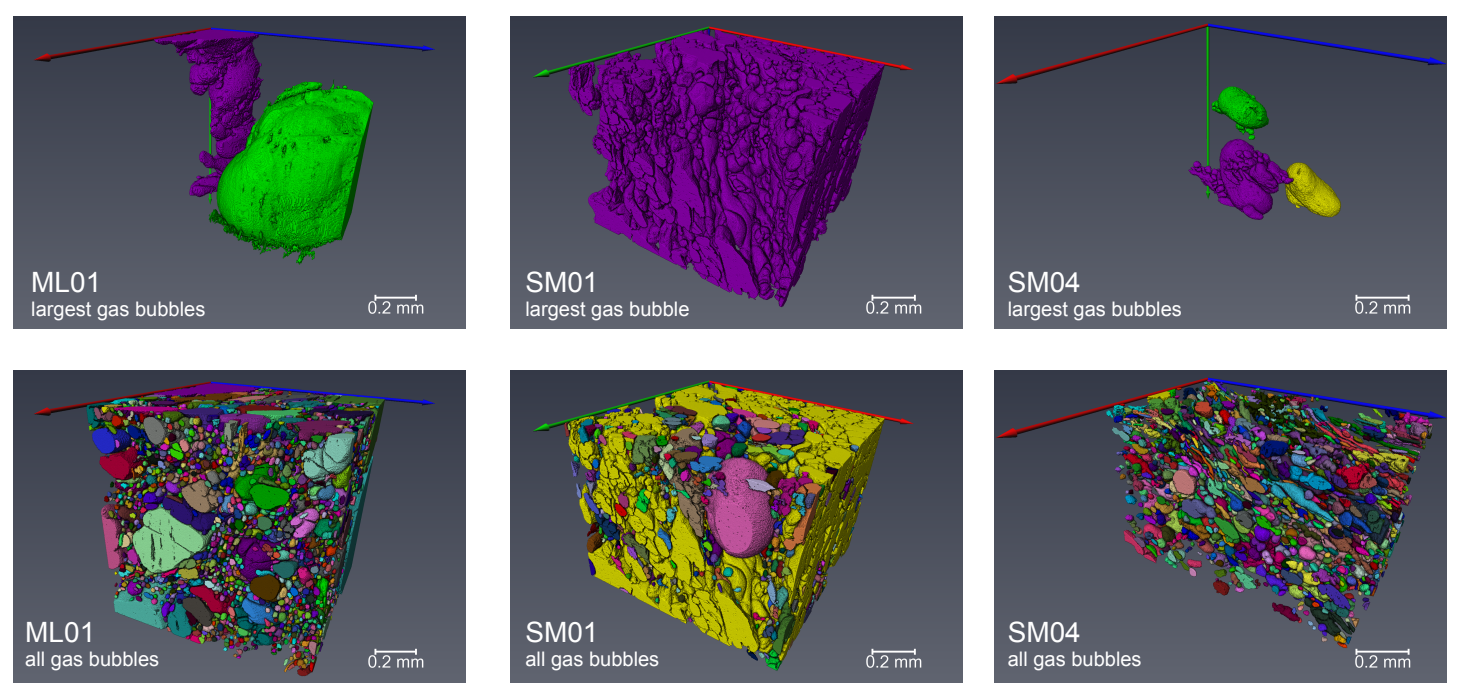

667

668 Figure 3: Shapes of trapped gas bubbles. 3D $\mu$ XRT images of trapped gas bubbles within

669 pumice. Colors in this figure are chosen at random to identify separate gas bubbles. The

670 top rows show the largest gas bubbles and the bottom row shows all gas bubbles within a

671 single pumice. A single interconnected gas bubbles extends throughout many pores in 672 pumice SM01.

673 

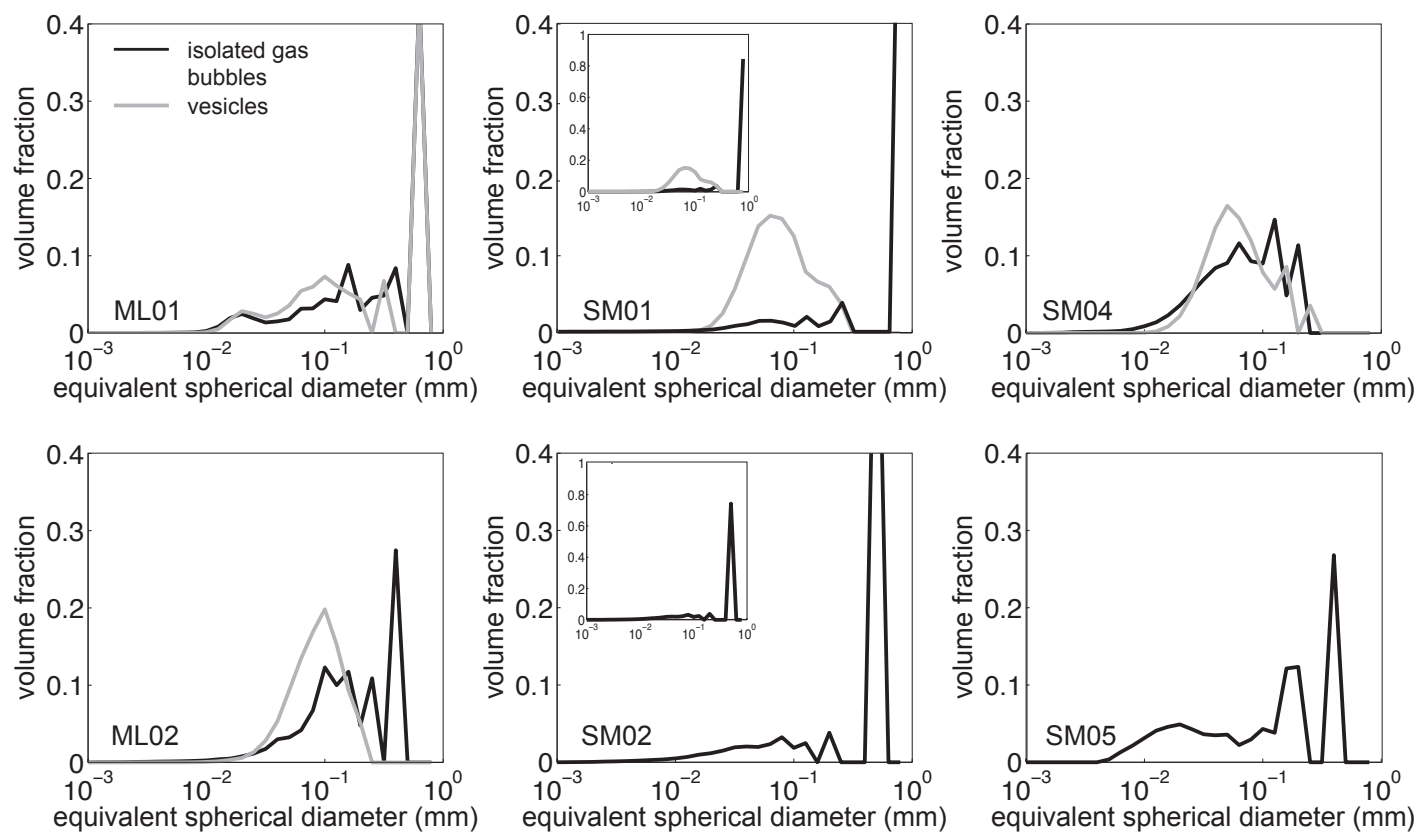

675 Figure 4: Bubble and vesicle size distributions. Trapped gas bubbles, locations where

676 only the gas is present, are shown in black, and vesicles, pumice pores that can be filled

677 with liquid or gas, are in grey. At least a third of the trapped gas is contained with a

678 single large bubble for most of samples. The existence of large trapped bubbles, in

679 combination with the vesicle size distribution, demonstrates that at least the largest gas

680 clusters often extend through multiple pores. Bubbles and vesicles are binned into fifty

681 logarithmically spaced bins and each bin is divided by the total volume of air or vesicles.

682 Volume fraction is not weighted by bin width such that the sum of all bins equals one. 

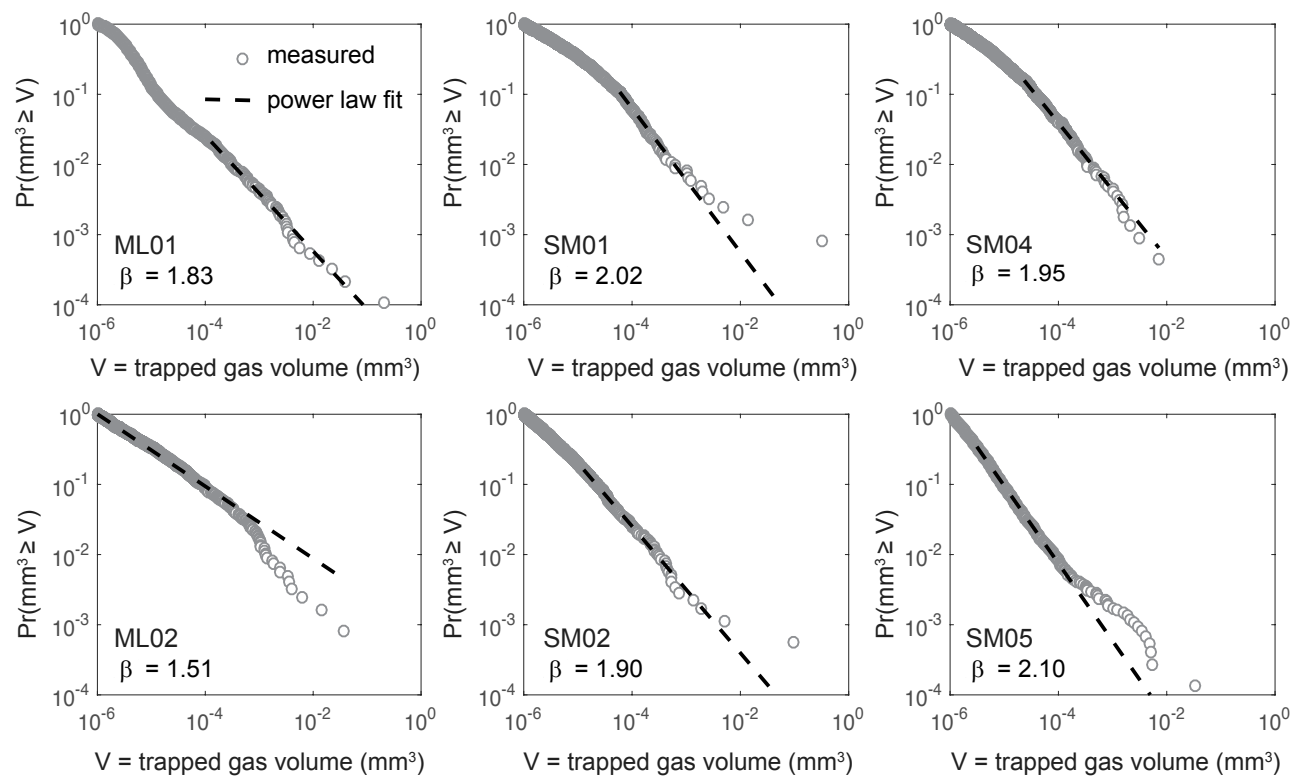

683

684 Figure 5: Power-law fits of bubble-size distributions. Measured distributions of trapped

685 bubble volume (grey circles) and the fitted power-law distributions (dashed lines). The y-

686 axis shows the probability that a bubble is larger than a given volume, $V$. With the

687 exception of ML02, the fitted power-law coefficients, $\beta$, are consistent with the value

688 predicted from percolation theory, $\beta=2.19$. Because our machine learning segmentation

689 method generated very small (artifact) bubbles, we removed bubbles smaller than $10^{-6}$

$690 \mathrm{~mm}^{3}$ before fitting a power-law coefficient.

691

692

693 


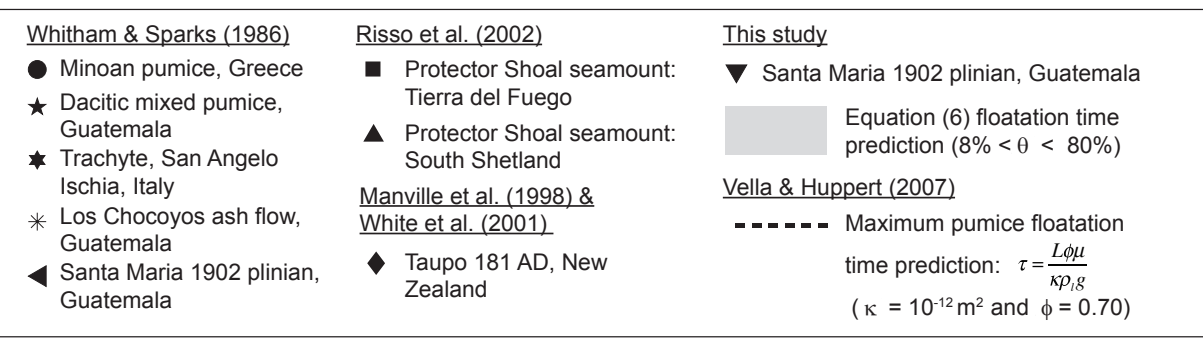

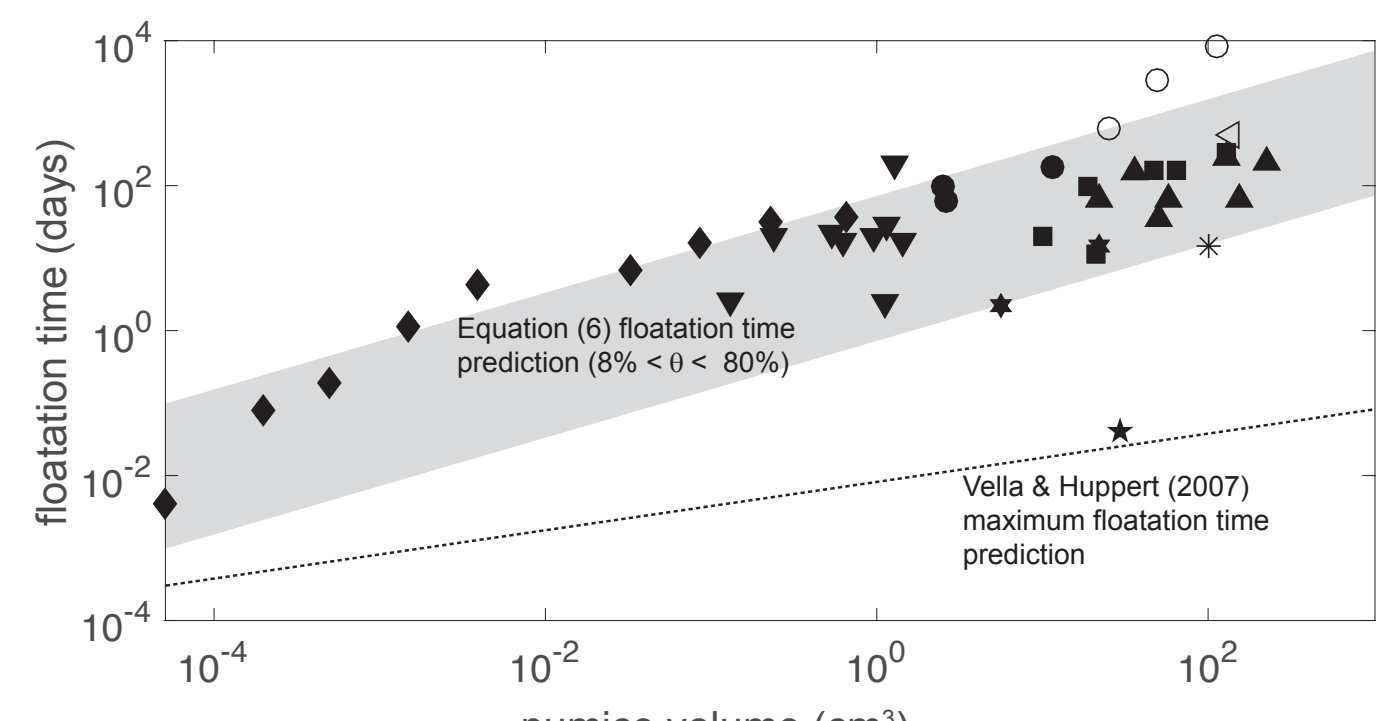

696 Figure 6: Floatation time as a function of pumice volume. Measurements of pumice

697 floatation from this study, Whitham \& Sparks (1986), Maneville et al. (1998), Risso et al.

698 (2002), and White et al. (2001). Pumice floatation time predictions from this study

699 (Equation 6) and Vella \& Huppert (2007) are also shown. Measured floatation times fit

700 the trend predicted by Equation (6) (grey bar). Filled symbols represent measured

701 sinking times while open symbols represent projected sinking times. 


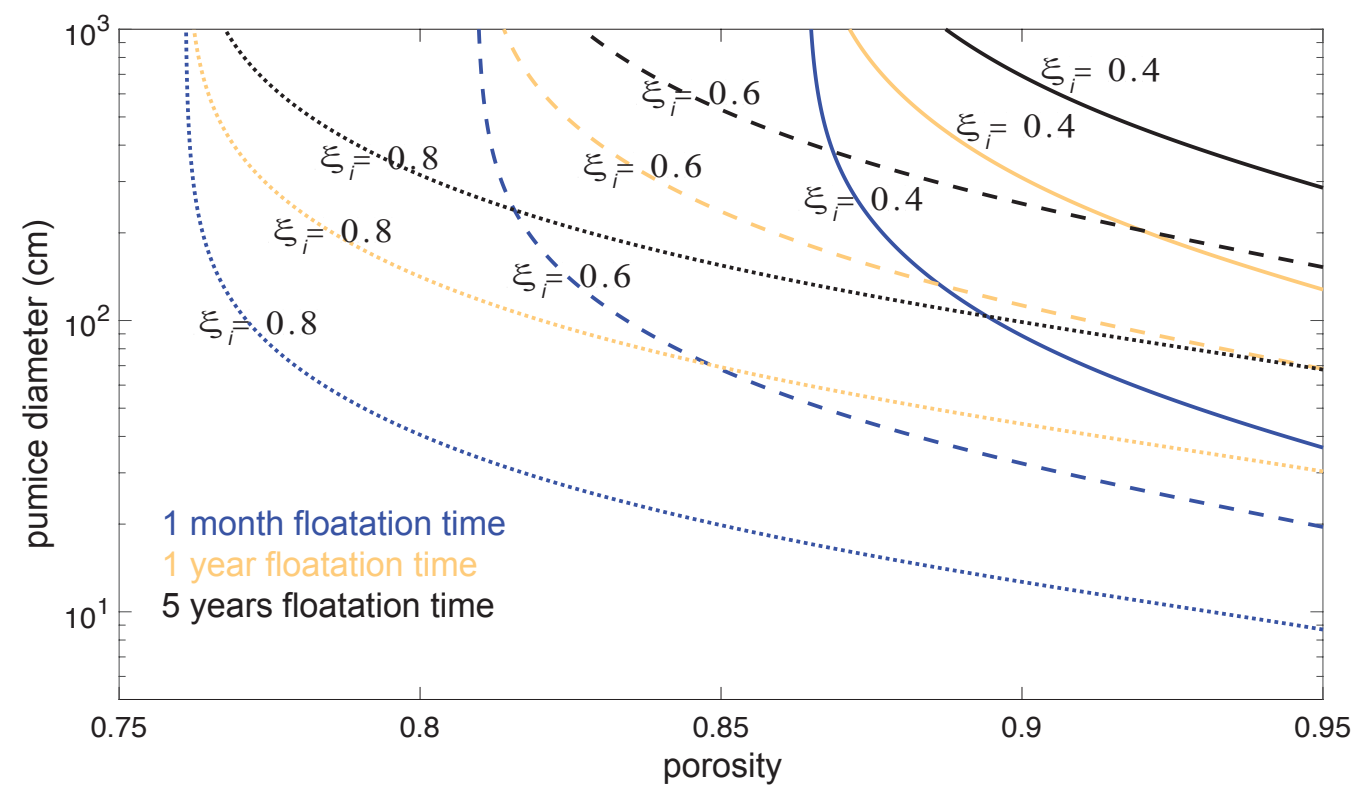

702

703 Figure 7: Floatation time as a function of clast size, porosity and initial saturation. We

704 plot solutions to Equations (14) and (15) to demonstrate how floatation time varies with

705 pumice size, porosity, and initial gas saturation, $\xi_{i}$. We assume $\rho_{r}=2.4 \mathrm{~g} \mathrm{~cm}^{-3}, \rho_{r}=1.0 \mathrm{~g}$

$706 \mathrm{~cm}^{-3}$, and sum the first ten terms of Equation (14).

707

708

709

710

711

712

713

714

715

716 
718 TABLES

719 Table 1: $\mu$ XRT samples (uncut clasts) and measurements

\begin{tabular}{|c|c|c|c|c|c|c|}
\hline sample name & SM01 & SM02 & SM04 & SM05 & ML01 & ML02 \\
\hline sample description & $\begin{array}{l}1902 \text { Santa } \\
\text { Maria }\end{array}$ & $\begin{array}{l}1902 \text { Santa } \\
\text { Maria }\end{array}$ & $\begin{array}{l}1902 \text { Santa } \\
\text { Maria }\end{array}$ & $\begin{array}{l}1902 \text { Santa } \\
\text { Maria }\end{array}$ & $\begin{array}{l}\text { Medicine } \\
\text { Lake }\end{array}$ & $\begin{array}{l}\text { Medicine } \\
\text { lake }\end{array}$ \\
\hline pumice mass (g) & 0.07 & 0.19 & 0.13 & 0.04 & 0.15 & 0.76 \\
\hline $\begin{array}{l}\text { pumice dimensions } \\
\text { mm }^{3}\end{array}$ & $9 \times 4.5 \times 4$ & $11 \times 7 \times 4.5$ & $11 \times 6 \times 5$ & $6.5 \times 3 \times 3$ & $9.5 \times 5 \times 5$ & $5 \times 5 \times 4$ \\
\hline temperature & ambient & ambient & $500{ }^{\circ} \mathrm{C}$ & $500{ }^{\circ} \mathrm{C}$ & ambient & ambient \\
\hline ending buoyancy & floating & $\begin{array}{c}\text { neutrally } \\
\text { buoyant }\end{array}$ & not floating & not floating & not floating & $\begin{array}{l}\text { barely } \\
\text { floating }\end{array}$ \\
\hline porosity & 0.70 & NA & 0.73 & NA & 0.63 & 0.67 \\
\hline connected porosity & 0.70 & NA & 0.73 & NA & 0.55 & 0.65 \\
\hline $\begin{array}{l}\text { liquid volume/ total } \\
\text { volume }\end{array}$ & 0.30 & NA & 0.56 & NA & 0.13 & 0.31 \\
\hline $\begin{array}{l}\text { gas volume/total } \\
\text { volume } \\
\text { liquid saturation } \\
\text { (liquid volume/pore } \\
\text { volume) }\end{array}$ & 0.40 & 0.36 & 0.17 & 0.13 & 0.50 & 0.36 \\
\hline $\begin{array}{l}\text { calculated wet density/ } \\
\text { KI density }\end{array}$ & 0.86 & NA & 1.07 & NA & 0.83 & 0.93 \\
\hline $\begin{array}{l}\text { trapped gas bubble } \\
\text { number density }\left(\mathrm{cm}^{-3}\right)\end{array}$ & $9.6 \times 10^{5}$ & $3.0 \times 10^{6}$ & $4.4 \times 10^{6}$ & $4.2 \times 10^{6}$ & $7.2 \times 10^{6}$ & $2.3 \times 10^{6}$ \\
\hline $\begin{array}{l}\text { vesicle number density } \\
\left(\mathrm{cm}^{-3}\right)\end{array}$ & $8.3 \times 10^{6}$ & NA & $1.5 \times 10^{7}$ & NA & $9.6 \times 10^{6}$ & $5.3 \times 10^{6}$ \\
\hline$\beta$ : Power law exponent & 2.02 & 1.90 & 1.95 & 2.10 & 1.83 & 1.51 \\
\hline $\begin{array}{l}\text { smallest bubble fit to } \\
\text { power law }\left(\mathrm{mm}^{3}\right) \\
p \text { : Trapped bubble } \\
\text { volume to surface area } \\
\text { exponent }\end{array}$ & $5.9 \times 10^{-5}$ & $1.3 \times 10^{-5}$ & $2.3 \times 10^{-5}$ & $3.1 \times 10^{-6}$ & $1.3 \times 10^{-4}$ & $1.0 \times 10^{-6}$ \\
\hline $\begin{array}{l}\text { size of analyzed volume } \\
\left(\mathrm{mm}^{3}\right)\end{array}$ & 0.94 & 0.37 & 0.37 & 0.94 & 0.94 & 0.37 \\
\hline
\end{tabular}

720 While $\mu$ XRT analysis is done on subvolumes of larger clasts, we expect the subvolumes

721 to be representative of the larger pumice in part because the pumice are relatively small 
722 (i.e., $<1 \mathrm{~g}$ ). Furthermore, the selected pumice samples do not have bread crust textures

723 such that we expect differences between rim an internal porosities to be minimal.

726 Table 2: Floatation time measurements for Santa Maria pumice.

\begin{tabular}{lccc}
\hline $\begin{array}{l}\text { sample } \\
\text { name }\end{array}$ & $\begin{array}{c}\text { dry weight } \\
(\mathrm{g})\end{array}$ & $\begin{array}{c}\text { estimated } \\
\text { volume }\left(\mathrm{cm}^{3}\right)\end{array}$ & \begin{tabular}{l} 
floatation time (days) \\
\hline SM_F02
\end{tabular} \\
0.30 & 0.63 & 17.3 \\
SM_F03 & 0.25 & 0.53 & 22.7 \\
SM_F05 & 0.46 & 0.95 & 20.2 \\
SM_F06 & 0.68 & 1.42 & 17.0 \\
SM_F09 & 0.61 & 1.28 & 195.5 \\
SM_F10 & 0.06 & 0.13 & 2.6 \\
SM_F11 & 0.55 & 1.15 & 28.2 \\
SM_F21 & 0.54 & 1.12 & 2.5 \\
SM_F22 & 0.12 & 0.24 & 20.1 \\
\hline
\end{tabular}

\section{Notation}

$730 v \quad$ velocity

$731 \mu \quad$ dynamic viscosity

$732 \gamma \quad$ surface tension

$733 \rho \quad$ density

$734 \quad g \quad$ gravity

$735 \kappa \quad$ permeability

$736 \phi \quad$ connected porosity

$737 h$ height

$738 \quad V_{w} \quad$ volume of water absorbed

$739 t \quad$ time

$740 S_{a} \quad$ pumice surface area

$741 \quad n \quad$ number of occurences

$742 \mathrm{~s} \quad$ sites or pores

$743 \quad \beta \quad$ power law coefficient

744 a spatial dimension

$745 f \quad$ fractal dimension a cluster

$746 s_{\max }$ maximum size of a trapped gas cluster

$747 L$ pumice diameter

$748 \quad A \quad$ surface area of trapped gas clusters

$749 \quad \mathrm{~V}$ trapped gas volume

$750 \quad p \quad$ power-law coefficient

$751 \tau \quad$ pumice floatation timescale

$752 D_{\text {eff }}$ effective diffusion coefficient 
$753 \theta \quad$ water saturation

$754 \quad D \quad$ liquid-gas diffusion coefficient

$755 d$ mean pore throat diameter

$756 \quad P \quad$ pressure

$757 R \quad R \quad$ pore throat radius

$758 \quad T \quad$ temperature

$759 L_{w} \quad$ glass wall thickness

$760 \quad D_{w} \quad$ water thermal diffusivity

$761 T_{i} \quad$ initial temperature

$762 T_{f} \quad$ final temperature

$763 V_{i} \quad$ initial volume

$764 V_{f} \quad$ final volume

$765 \xi \quad$ gas saturation

$766 \quad \xi_{i} \quad$ initial gas saturation

$767 \quad \xi^{*} \quad$ neutral buoyancy gas saturation

$768 \rho_{r} \quad$ glass density

$769 \rho_{l} \quad$ liquid density 